\title{
Predictors of Utilization of Skilled Birth Attendants Among Women of Reproductive Age in Mandera East Sub County, Mandera County, Kenya
}

\author{
Hassan Ali Ibrahim ${ }^{1}$, Ademola Johnson Ajuwon², Adesina Oladokun ${ }^{3}$ \\ ${ }^{1}$ Department of Reproductive Health, Pan African University, University of Ibadan, Ibadan, Nigeria \\ ${ }^{2}$ Department of Health Promotion and Education, University College Hospital (UCH), University of Ibadan, Ibadan, Nigeria \\ ${ }^{3}$ Department of Obstetrics and Gynecology, University College Hospital (UCH), University of Ibadan, Ibadan, Nigeria
}

Email address:

hasani3170@gmail.com (H. A. Ibrahim), ajajuwon@yahoo.com (A. J. Ajuwon), sinaoladokun@yahoo.com (A. Oladokun)

To cite this article:

Hassan Ali Ibrahim, Ademola Johnson Ajuwon, Adesina Oladokun. Predictors of Utilization of Skilled Birth Attendants Among Women of Reproductive Age in Mandera East Sub County, Mandera County, Kenya. Science Journal of Public Health.

Vol. 5, No. 3, 2017, pp. 230-239. doi: 10.11648/j.sjph.20170503.21

Received: February 27, 2017; Accepted: March 11, 2017; Published: March 31, 2017

\begin{abstract}
The single most critical intervention in the reduction of maternal mortality is to ensure that a health worker with appropriate skills is present during pregnancy, delivery and time after delivery. The main objective of the study was to determine predictors of the utilization of skilled birth attendants among women of reproductive age in Mandera East Sub County, Kenya. The cross-sectional descriptive study consisted of use of both the qualitative and quantitative approaches for data collection. Quantitative data were collected using interviewer administered questionnaire, among 365 randomly selected consenting women who delivered a baby a year prior to the conduct of the research. Qualitative data were collected through indepth interviews of nine women including three who utilized skilled birth attendants and six who did not. Quantitative data were analyzed using SPSS software while qualitative data from in depth interview were analyzed thematically and corroborated with results from questionnaire. Data were analyzed using Chi-square test and logistical regression to identify independent predictors of utilization of skilled birth attendants. A p-value of $<0.05$ was considered significant. The ages of the respondents ranged from $15-49$ years with a mean of $27 \pm 1.391$ years. The results showed antenatal attendance of $84.4 \%$ while the proportion of birth attended by Skilled Birth Attendant was low (37.8\%) among women of reproductive age in Mandera East. The main predictors of utilization of skilled birth attendants were: education level of the mother, type of occupation of the mother, household income, transport to the facility, parity, reliability of transport at odd hours, occupation of husbands and decision making. Barriers to utilization of SBAs included: Availability and convenience of TBAs, poor staff attitude, limited number of SBAs, poor and unreliable transport especially at night, poor referral system, cultural beliefs and misconceptions. Despite the attendance of ANC clinics being high, the level of utilization of skilled birth attendants among the study population was still low with high number of deliveries still conducted by unskilled persons at home. This study recommends that the county government should come up with strategies of ensuring that women have access to education such as Adult Education Programme; economic empowerment of women through Business enterprises; provide attraction and retention package for healthcare staffs especially SBAs; Provision of incentives to TBAs for referral of pregnant women to the facility; Strengthen referral system especially in hard to reach areas.
\end{abstract}

Keywords: Skilled Birth Attendants, Antenatal Care, Traditional Birth Attendants, Maternal Mortality

\section{Introduction}

Skilled Birth Attendance (SBA) and access to emergency obstetric care, when required, are the two most critical interventions needed to ensure safe motherhood [1].
Worldwide, about one third of births take place without the assistance of skilled health personnel. In 2013 alone, this translated into more than 40 million unattended births, over 80 per cent of which were in South Asia and sub-Saharan Africa [1]. These two regions together account for over 85 
per cent of all maternal deaths worldwide with the lowest levels of skilled attendance at birth. Regional averages range from about 50 per cent in South Asia and sub-Saharan Africa to a high of 99 per cent in Central and Eastern Europe and the Commonwealth of Independent States [2].

Despite substantial progress over the last two decades, inadequate or non-existent care during pregnancy and delivery is largely responsible for the annual deaths of an estimated 289,000 mothers and 2.8 million newborns in the first month of life. Indeed, roughly three quarters of all maternal deaths take place during delivery and in the immediate postpartum period [1]. In order to improve maternal and newborn survival, skilled health personnel (a doctor, nurse or midwife) capable of handling normal deliveries, recognize warning signs of complications and refer the mother to emergency care should be present. Nonskilled attendants, including traditional birth attendants, whether trained or untrained, can neither predict nor cope with serious complications such as hemorrhage or sepsis, which are the leading killers of mothers during and after childbirth [1].

In Africa, each year about 30 million women become pregnant, yet $60 \%$ (18 million women) give birth at home without the assistance of skilled birth attendants [3]. For example, despite the existence of modern health facilities in Nigeria, approximately $60 \%$ of deliveries still take place at home whereas only $37 \%$ take place in hospitals [4]. It is estimated that about 250,000 women die from pregnancy related causes and approximately 280,000 babies die of birth asphyxia soon after birth [3]. Within countries, there are great disparities in the use of skilled care; for example a study conducted by Fekadu and Regassa in Ethiopia to analyze urban-rural differentials in the utilization of SBA found that only $15.6 \%$ received skilled delivery care services either at home or at health institution. Rural women were at greater disadvantage to receive the service, as only $4.5 \%$ women in rural areas received assistance from SBAs compared to $64.1 \%$ of their urban counter-parts. This inequality is also linked to education levels and rural residence. In rural areas amenities such as schools and health facilities are either non-existent or often spread out over vast distances with rudimentary transportation compared to urban areas [5]. In Nigeria, a country with more than 160 million people, about $70 \%$ of its population reside in the rural areas that lack basic amenities of life; good road networks, portable drinking water and adequate health facilities. The inadequacy of health care facilities and services propagates the existence of TBAs.

In Kenya, Maternal Mortality Ratio (MMR) remain high, with 488 deaths per every 100,000 live births per year [6], largely because women do not give birth under the care of skilled health providers. High maternal deaths are attributed to well-known and preventable causes, including: obstructed labour, complications of unsafe abortion, infections, hemorrhage and high blood pressure. Most of these deaths could be avoided if the mother is managed at a health facility by a qualified health professional.

At 3795 per 100,000 live births, Mandera County has one of the unacceptably high MMR and under five mortality rate of 80/1000 live births [7] in Kenya. Mandera County has 38.7\% deliveries attended by skilled birth attendants and health care deliveries accounts for only $36 \%$ [8]. Home delivery is a frequent practice where an estimated $65 \%$ of women in the rural area give birth with traditional birth attendants (TBA), some of whom have very little delivery care skills [8].

The persistently and unacceptably high maternal mortality in the area was attributed to lack of access to maternal health services, long span of marginalization, insecurity, weak health systems and negative cultural practices. Moreover, there is lack of adequate data on contextual factors that led to low utilization of skilled delivery in the County as previous studies used mainly quantitative methods. A thorough understanding of the importance of local barriers and facilitating factors for the use of skilled delivery is a prerequisite for designing and implementing interventions that aim to improve access. The main objective of this study was to determine predicting factors of utilization of skilled birth attendants among women of reproductive age in Mandera East and the results are expected to inform policy formulation and developments of interventions aimed at improving uptake of skilled delivery services and reducing maternal mortality in the county.

\section{Methods}

\subsection{Study Setting}

Mandera County, the setting for the study, covers an area of $25,991 \mathrm{~km}^{2}$. It shares international borders with Ethiopia to the north, Somalia to the east and nationally borders with Wajir County to the south. According to the Kenya National Bureau of Statistics (KNBS) 2009, the county has a total population of $1,025,756$; female accounts for $465,813(45 \%)$ while males are 559,943 (55\%).

The County is largely semi-arid and most areas lack a permanent water source or water mass and report low rainfall throughout the year. Main residents are Kenyan Somali ethnic communities the majority of whom are Muslims whose main economic activities include: livestock keeping, trade, agro pastoralism. Harsh climatic conditions and poorly developed infra-structure make the county one of the most marginalized in the country.

The county has six sub counties and six parliamentary constituencies, 30 wards and 148 villages. Data were collected from Mandera East sub County with a total population of 178,831 with Women of Reproductive age accounting for $31.3 \%$ [9]. The study sub-county (Mandera East) was purposively selected due to its cosmopolitan nature (It has different ethnic communities). The Sub County is also home to Mandera County Referral Hospital and has 10 primary health centres and dispensaries.

\subsection{Sample Size Determination and Sampling Procedure}

The sample size was estimated to be 365 using Fisher's et al, 2003 Formula. The sub-county has five (5) wards and 
three (3) of the wards namely Khalalio, Neboi and Township were selected randomly through balloting. These wards are fairly heterogeneous in their ethnic composition representing all communities living in Mandera County.

Households in the study areas were mapped and through systematic random sampling, every third house from the starting point was identified and women who delivered in the last 12 months prior to the commencement of study selected and interviewed. Where there were more than one eligible respondent in one household only one was selected randomly through balloting and interviewed. The eligible respondents in each ward were interviewed to give the required sample of 365

The sampling distribution was based on proportionate allocation where the ward with highest population will have the highest number of questionnaires, thus the population in the wards were 177, 118 and 70 from Neboi, Township and Khalalio respectively.

\subsection{Data Collection Tools and Procedure}

\subsubsection{Quantitative Data}

Trained interviewers used a structured questionnaire to conduct face-to-face interviews in Somali language which was transliterated into English with study participants. Faceto-face method of interview was adopted because the women were low literate persons. The questionnaire was divided into three sections. The first section was on the Sociodemographic and economic characteristics of the respondents; the second section was on the knowledge of ANC and attitude towards skilled delivery and the third section on the barriers towards utilization of skilled delivery.

\subsubsection{Qualitative Data}

Participants for the in-depth interviews were identified from the survey component of the study. The in-depth interviews were conducted with nine women who were identified from the quantitative component of the study. These included three (3) women, one from each of the ward who also reported to have utilized skilled birth attendants and six women (2 from each ward) who reported non-use of SBA. The purpose of the in-depth interviews was to gain insights into the reasons for utilization and non-utilization of SBA services.

\subsection{Data Management and Analysis}

Completed questionnaires were screened every day to identify incomplete, incorrect and inaccuracies in data and errors corrected. The raw data were cleaned, re-coded and entered into SPSS database. Quick frequency and summary statistics were computed to check for implausible entries and errors corrected.

The processing and analysis of data was done using SPSS (version 22). Descriptive statistics such as frequencies and percentages were used to organize and summarize quantitative variables and presented inform of frequency tables, bar charts and pie charts, tables, figures and narration.

The tools for analysis used in inferential statistics were mainly chi-square and binary logistical regression. $\mathrm{P}$-values of less than 0.05 were considered statistically significant. Qualitative data from in-depth interview was transcribed and analyzed thematically. Major themes from the interview were identified and corroborated with the results from quantitative data.

\subsection{Ethical Approval}

The study protocol was approved by the University of Ibadan/University College Hospital Ethics Review Committee in Ibadan Nigeria and the Kenyatta University Ethical Review Committee, Nairobi, Kenya. Permission to carry out the research was obtained from the National Commission for Science, Technology and Innovation (NACOSTI), Kenya. Informed consents were obtained from each respondents after they were informed about the purpose of the study, the procedures involved, that data collected will be kept confidential and that their participation was voluntary.

\section{Results}

\subsection{Demographic Profile of Respondents}

The ages of the respondents ranged from 15-49 years with a mean of $27 \pm 1.391$ years. Majority of the respondents $26.0 \%(n=95)$ belong to the 25-29 age group (Table 1). Age category differs among the three different wards with majority of the 25-29 years registered in Neboi ward $(12.6 \%$ out of $26 \%$ ), Adolescent mothers make $9.9 \%$. The majority of women $(51 \%)$ had no education. The differences in educational level of mothers were registered across the different wards with Neboi being high, followed by Township and Khalalio lowest. On occupation, $52.7 \%$ of the respondents were not working and $18.6 \%$ were government employees. A large majority $(92 \%)$ of the women were married (Table 2).

Table 1. Socio-Demographic characteristics of the respondents $(n=365)$.

\begin{tabular}{|c|c|c|c|c|c|c|c|c|c|}
\hline \multicolumn{10}{|c|}{ Wards } \\
\hline \multirow{2}{*}{ Characteristic } & \multirow{2}{*}{ Category } & \multicolumn{2}{|c|}{ Township } & \multicolumn{2}{|c|}{ Neboi } & \multicolumn{2}{|c|}{ Khalalio } & \multirow{2}{*}{ Total frequency (n) } & \multirow{2}{*}{ Total percentage $(\%)$} \\
\hline & & $\mathbf{N}$ & $\%$ & $\mathbf{n}$ & $\%$ & n & $\%$ & & \\
\hline \multirow{8}{*}{ Age } & Mean age $=27 \pm 1.391$ years & 29 & & 27 & & 25 & & & \\
\hline & $15-19$ & 12 & 3.3 & 17 & 4.7 & 7 & 1.9 & 36 & 9.9 \\
\hline & $20-24$ & 28 & 7.7 & 42 & 11.5 & 17 & 4.7 & 87 & 23.8 \\
\hline & $25-29$ & 31 & 8.5 & 46 & 12.6 & 18 & 4.9 & 95 & 26.0 \\
\hline & $30-34$ & 28 & 7.7 & 42 & 11.5 & 17 & 4.7 & 86 & 23.7 \\
\hline & $35-39$ & 11 & 3.0 & 16 & 4.4 & 6 & 1.6 & 33 & 9.0 \\
\hline & $40-44$ & 8 & 2.2 & 12 & 3.3 & 5 & 1.4 & 25 & 6.8 \\
\hline & $45-49$ & 0 & 0 & 2 & 0.5 & 1 & 0.3 & 3 & 0.8 \\
\hline
\end{tabular}




\begin{tabular}{|c|c|c|c|c|c|c|c|c|c|}
\hline \multicolumn{10}{|c|}{ Wards } \\
\hline \multirow{2}{*}{ Characteristic } & \multirow{2}{*}{ Category } & \multicolumn{2}{|c|}{ Township } & \multicolumn{2}{|c|}{ Neboi } & \multicolumn{2}{|c|}{ Khalalio } & \multirow{2}{*}{ Total frequency (n) } & \multirow{2}{*}{ Total percentage (\%) } \\
\hline & & $\mathbf{N}$ & $\%$ & $\mathrm{n}$ & $\%$ & $\mathbf{n}$ & $\%$ & & \\
\hline \multirow{4}{*}{$\begin{array}{l}\text { Education } \\
\text { (Mother) }\end{array}$} & Primary & 29 & 8.0 & 30 & 8.2 & 14 & 3.8 & 73 & 20.0 \\
\hline & Secondary & 26 & 7.1 & 28 & 7.7 & 12 & 3.2 & 66 & 18.0 \\
\hline & College/ university & 16 & 4.4 & 17 & 4.7 & 7 & 1.9 & 40 & 11.0 \\
\hline & None & 47 & 12.9 & 102 & 28.0 & 37 & 10.1 & 186 & 51.0 \\
\hline \multirow{6}{*}{$\begin{array}{l}\text { Occupation } \\
\text { (Mother) }\end{array}$} & No work & 57 & 15.6 & 95 & 26.0 & 40 & 11 & 192 & 52.7 \\
\hline & Farming & 1 & 0.3 & 2 & 0.5 & 2 & 0.5 & 5 & 1.3 \\
\hline & Trading/Selling & 12 & 3.3 & 14 & 3.8 & 2 & 0.5 & 28 & 7.8 \\
\hline & Government employee & 28 & 7.7 & 31 & 8.5 & 9 & 2.5 & 68 & 18.6 \\
\hline & Labourer/Casual worker & 6 & 1.6 & 14 & 3.8 & 9 & 2.5 & 29 & 7.8 \\
\hline & Others & 15 & 4.1 & 21 & 5.8 & 7 & 1.9 & 43 & 11.8 \\
\hline
\end{tabular}

Regarding husbands' level education, $38.6 \%$ had no education at all and majority $(32.3 \%)$ of the husbands were traders and $19.6 \%$ government employees (Table 2).

Table 2. Husbands' level of education and occupation $(n=336)$.

\begin{tabular}{ll}
\hline Husbands' education level & Percentage \\
\hline Primary & 21.7 \\
Secondary & 19.3 \\
College/university & 16.3 \\
None & 38.6 \\
Others (non-formal) & 4.2 \\
Occupation of husband & \\
No work & 12.5 \\
Farming & 8.9 \\
Trading/selling & 32.3 \\
Government employee & 19.6 \\
Carpenter & 5.9 \\
Labourer/casual worker & 13.6 \\
Others $($ Quranic/ Madarasa teachers etc) & 7.1 \\
\hline
\end{tabular}

Majority of the respondents $(25.5 \%)$ reported their income to be between $\$ 50-\$ 150$. The highest income of $\$ 500+$ was reported by $16.4 \%$ of the respondents. This is shown in the figure 1 below.

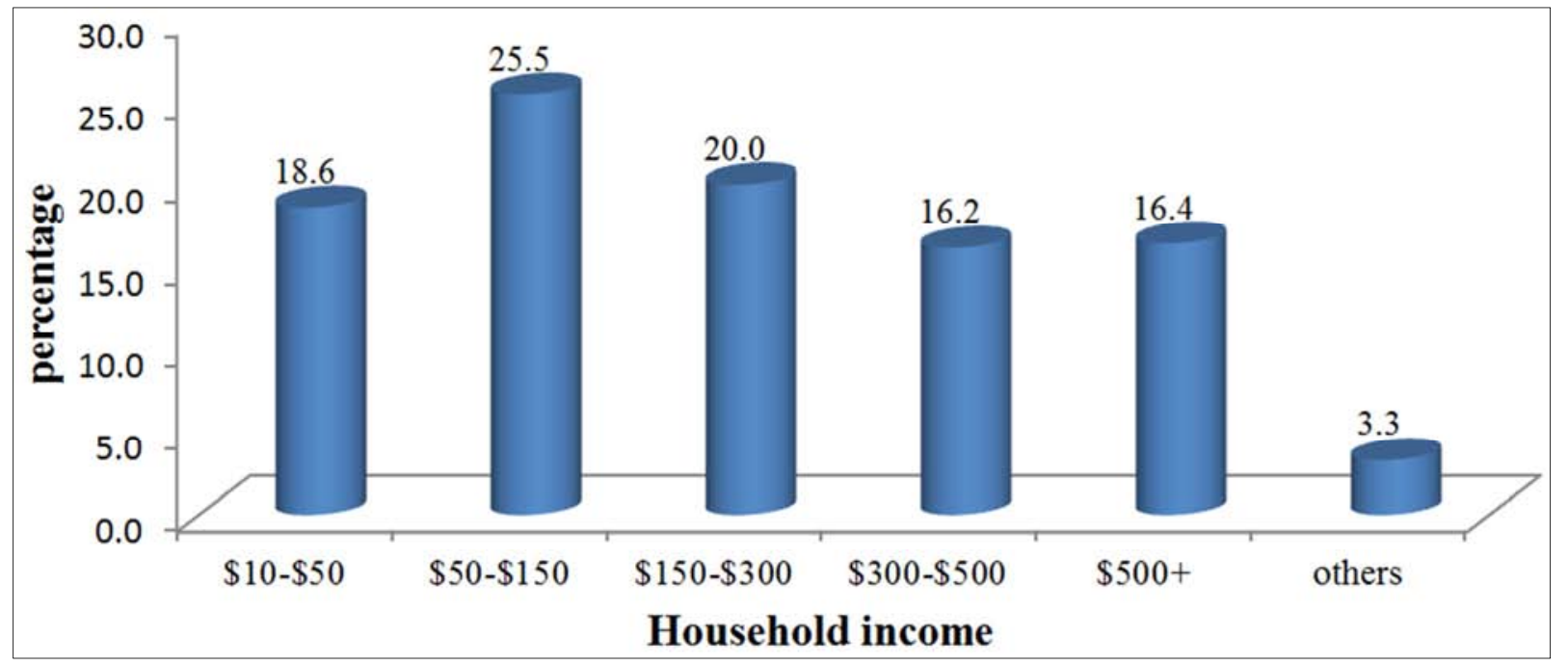

*Others: those who had monthly income less than $\$ 10.0$.

Figure 1. Respondents' Monthly Household Income.

\subsection{Antenatal Care Services Received During Last Pregnancy}

The majority of the respondents (84.4\%) reported that they attended ANC whereas only $15.6 \%$ did not attend (Figure 2 ). 


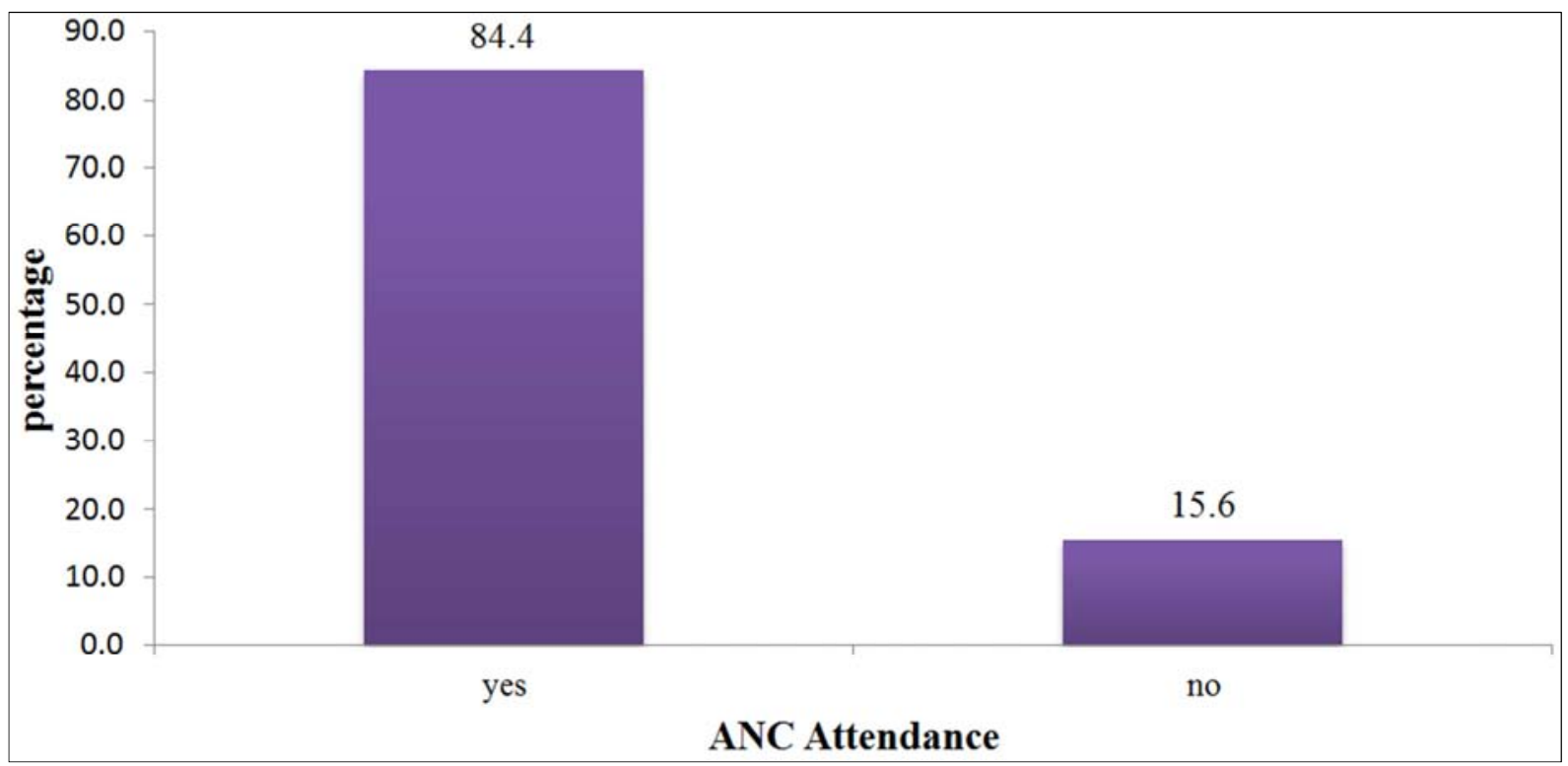

Figure 2. ANC Attendance.

All those who reported having attended ANC clinics $\mathrm{n}=308(84.4 \%)$ attended them in public health facilities. With regards to the number of clinics attended, majority (40.5\%) attended $1^{\text {st }}$ ANC, this was followed by $2^{\text {nd }}$ ANC clinic $(23.2 \%), 3^{\text {rd }}$ ANC visit at $10.2 \%$ and $4^{\text {th }}$ ANC at $5.4 \%$. On the information received at ANC majority of the respondents said they received information on danger signs and where to go in case of experience of any danger signs, where to give birth and arrangement for transport.

A large majority $(79.3 \%)$ of those attended ANC clinic said they had individual birth plan $20.7 \%$ did not make such plan. The main plans included: saving money (57.1\%), buying essential items for delivery (33.2\%), transport arrangements $(32.2 \%)$.

\subsection{Information on Last Delivery of the Respondents}

On the parity of the mothers, majority of the mothers (36.7\%) had a range of $1-2$ children followed by those who reported having 3-5 children $(35.1 \%)$ and those who had more than 5 children were $28.2 \%$. The majority of the respondents delivered their last child at TBA's home (46.9\%) or in their own house $(14.5 \%)$. Those who delivered at health facility represented $35.6 \%$ (Figure 3 ).

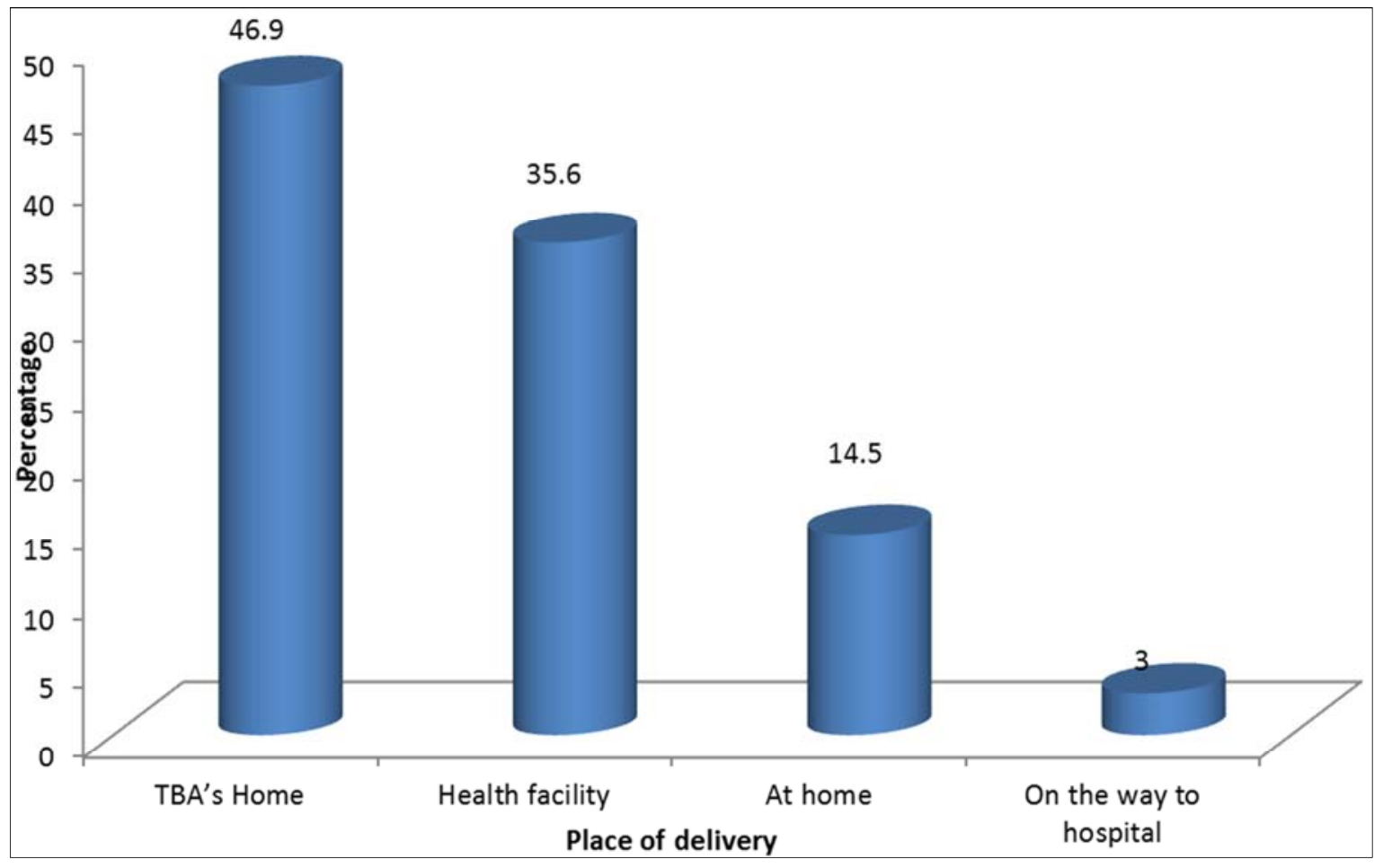

Figure 3. Place of Last Child Birth. 


\subsection{Delivery Assistants}

The majority of the respondents (59.4\%) were assisted by traditional birth attendants and $37.8 \%$ delivered under the care and assistance of skilled birth attendants (Figure 4).

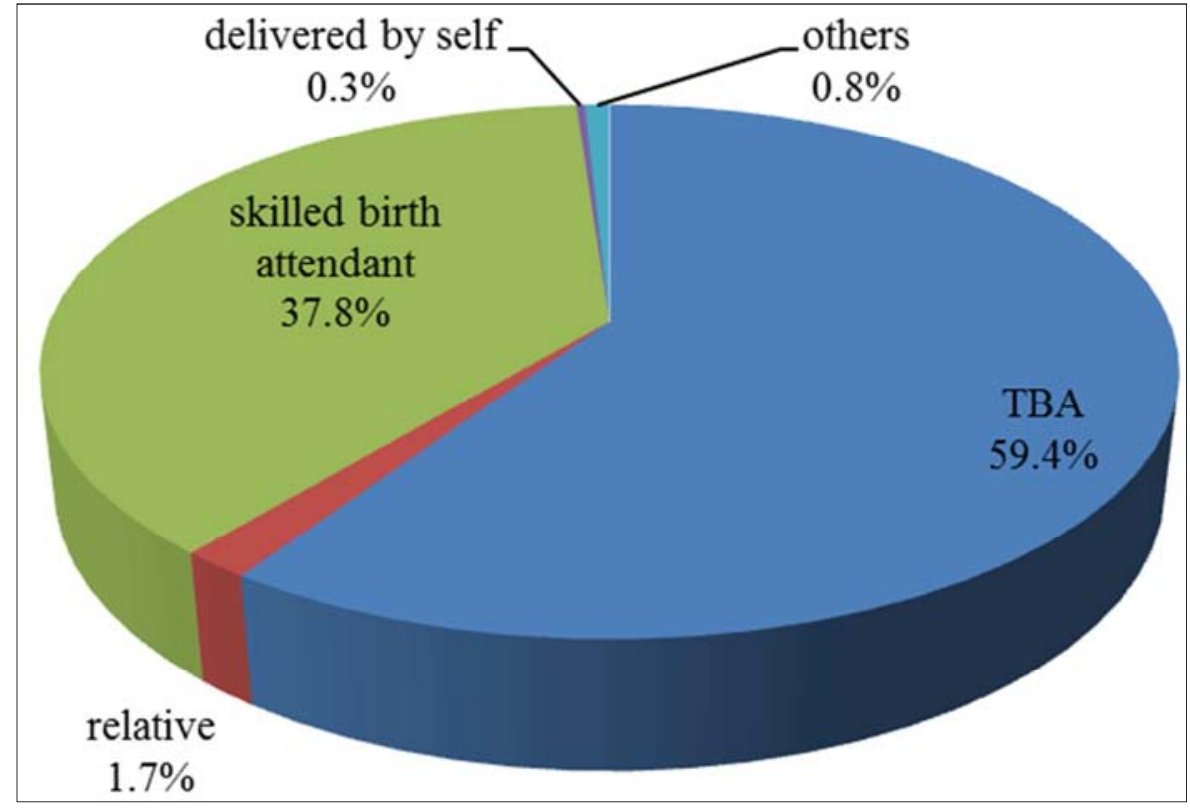

Figure 4. Delivery assistants.

The respondents were further asked of their preferred place for future delivery majority of them preferred health facilities with $39.3 \%$ of them preferring referral hospital and $37.6 \%$ still preferring TBA's home. The study also revealed that $50.7 \%$ of the respondents preferred health personnel for future delivery while $48.7 \%$ preferred TBA and $0.6 \%$ preferred other forms of delivery assistance. The reasons for preference of different delivery assistants is shown in table 3.

Table 3. Reasons for Preference of Delivery Assistance.

\begin{tabular}{lll}
\hline Reasons & Frequency (n) & Percent (\%) \\
\hline staff/ skills/drugs & 231 & 63.3 \\
staff can handle complications & 123 & 33.7 \\
TBA is helpful & 40 & 11.0 \\
TBA provide confidentiality & 12 & 3.3 \\
TBA show respect/sympathy & 23 & 6.3 \\
\hline
\end{tabular}

\subsection{Socio-Demographic and Economic Factors Associated with Utilization of $S B A$}

Chi-square test was used to determine if there was significant difference among independent variables in choices of skilled birth attendants by women. The result had significance levels as indicated in table 4 and 5 below. More educated women had significantly used SBA than there nonliterate counterparts; similarly government employees had significantly used SBA than others; women whose husbands' are more educated and government employees had significantly used SBA than their counterparts also women with higher household income had significantly used SBA than others.

Table 4. Socio-Demographic and economic factors influencing utilization of SBAs.

\begin{tabular}{|c|c|c|c|c|}
\hline \multicolumn{5}{|c|}{ Delivery by Skilled Birth Attendants } \\
\hline Variable & Category & Yes. n (\%) & No. $n(\%)$ & $\chi^{2}$ value (df) P-value \\
\hline \multirow{7}{*}{ Age } & $15-19$ & $15(41.7)$ & $21(58.3)$ & \multirow{7}{*}{$\begin{array}{l}\chi^{2} 7.602(6) \\
\mathrm{P}=0.269\end{array}$} \\
\hline & $20-24$ & $41(47.1)$ & $46(52.9)$ & \\
\hline & $25-29$ & $38(40)$ & $57(60)$ & \\
\hline & $30-34$ & $25(29)$ & $61(71)$ & \\
\hline & $35-39$ & $10(30.3)$ & $23(69.7)$ & \\
\hline & $40-44$ & $8(32)$ & $17(68)$ & \\
\hline & $45-49$ & $1(33.3)$ & $2(66.7)$ & \\
\hline \multirow{5}{*}{ Education level of the mother } & Primary & $32(42.1)$ & $44(57.9)$ & \multirow{5}{*}{$\begin{array}{l}\chi^{2}=199.48 \\
P<0.0001\end{array}$} \\
\hline & Secondary & $28(84.8)$ & $5(15.2)$ & \\
\hline & College/University & $61(98.4)$ & $1(1.6)$ & \\
\hline & None & $16(8.3)$ & $176(91.7)$ & \\
\hline & Others & $1(50)$ & $1(50)$ & \\
\hline
\end{tabular}




\begin{tabular}{|c|c|c|c|c|}
\hline & & Delivery b & ndants & \multirow{7}{*}{$\begin{array}{l}\chi^{2}=153.33(5) \\
P<0.0001\end{array}$} \\
\hline \multirow{6}{*}{ Occupation of the mother } & No work & $39(20.0)$ & $156(80.0)$ & \\
\hline & Farming & $1(16.7)$ & $5(83.3)$ & \\
\hline & Trading & $14(45.2)$ & $17(54.8)$ & \\
\hline & Government employee & $64(98.5)$ & $1(1.5)$ & \\
\hline & Labourer /Casual & $17(63.0)$ & $10(37.0)$ & \\
\hline & Others & $3(7.3)$ & $38(92.7)$ & \\
\hline \multirow{4}{*}{ Marital status } & Single & $2(28.6)$ & $5(71.4)$ & \multirow{4}{*}{$\begin{array}{l}\chi^{2}=8.25 \\
\mathrm{P}=0.041\end{array}$} \\
\hline & Married & $134(39.8)$ & $203(60.2)$ & \\
\hline & Divorced & $1(6.3)$ & $15(93.7)$ & \\
\hline & Widowed & $1(20.0)$ & $4(80.0)$ & \\
\hline \multirow{5}{*}{ Husbands' level of education } & Primary & $13(17.8)$ & $60(82.2)$ & \multirow{5}{*}{$\begin{array}{l}\chi^{2}=105.19 \\
\mathrm{P}<0.0001\end{array}$} \\
\hline & Secondary & $28(43.1)$ & $37(56.9)$ & \\
\hline & College/University & $47(85.5)$ & $8(14.5)$ & \\
\hline & None & $19(14.6)$ & $111(85.4)$ & \\
\hline & Others & $10(71.4)$ & $4(28.6)$ & \\
\hline \multirow{7}{*}{ Husbands' occupation } & No work & $15(35.7)$ & $27(64.3)$ & \multirow{7}{*}{$\begin{array}{l}\chi^{2}=69.66(6) \\
P<0.0001\end{array}$} \\
\hline & Farming & $1(3.3)$ & $29(96.7)$ & \\
\hline & Trading & $45(41.3)$ & $64(58.7)$ & \\
\hline & Government employee & $51(77.3)$ & $15(22.7)$ & \\
\hline & Carpenter & $4(20.0)$ & $16(80.0)$ & \\
\hline & Labourer /Casual & $11(23.9)$ & $35(76.1)$ & \\
\hline & Others & $4(16.7)$ & $20(83.3)$ & \\
\hline \multirow{6}{*}{ Household income } & $\$ 10-50$ & $10(14.7)$ & $58(85.3)$ & \multirow{6}{*}{$\begin{array}{l}\chi^{2}=108.60 \\
\mathrm{P}<0.0001\end{array}$} \\
\hline & $\$ 50-150$ & $13(14)$ & $80(86.0)$ & \\
\hline & $\$ 150-300$ & $31(42.5)$ & $42(57.5)$ & \\
\hline & $\$ 300-500$ & $34(57.6)$ & $25(42.4)$ & \\
\hline & $\$ 500+$ & $50(83.3)$ & $10(16.7)$ & \\
\hline & Others & $0(0.0)$ & $12(100)$ & \\
\hline \multirow{3}{*}{ Number of Children } & $1-2$ & $87(64.9)$ & $47(35.1)$ & \multirow{3}{*}{$\begin{array}{l}\chi^{2}=67.26(2) \\
\mathrm{P}<0.0001\end{array}$} \\
\hline & $3-5$ & $32(25)$ & $96(75)$ & \\
\hline & $>5$ & $19(18.4)$ & $84(81.6)$ & \\
\hline \multirow{4}{*}{$\begin{array}{l}\text { Decision making about place } \\
\text { of delivery }\end{array}$} & Myself & $63(31.2)$ & $139(68.8)$ & \multirow{4}{*}{$\begin{array}{l}\chi^{2}=12.97 \\
\mathrm{P}=0.005\end{array}$} \\
\hline & Husband & $53(46.1)$ & $62(53.9)$ & \\
\hline & Mother-in-law & $21(52.5)$ & $19(47.5)$ & \\
\hline & Relatives & $1(12.5)$ & $7(87.5)$ & \\
\hline \multirow{4}{*}{ Duration taken to the facility } & Half an hour & $57(39.6)$ & $87(60.4)$ & \multirow{4}{*}{$\begin{array}{l}\chi^{2}=1.769(3) \\
\mathrm{P}=0.623\end{array}$} \\
\hline & 1 hour & $54(34.2)$ & $104(65.8)$ & \\
\hline & 2 hours & $24(42.9)$ & $32(57.1)$ & \\
\hline & Others & $3(42.9)$ & $4(57.1)$ & \\
\hline \multirow{4}{*}{$\begin{array}{l}\text { Means of reaching health } \\
\text { facility }\end{array}$} & Own car & $21(61.8)$ & $13(38.2)$ & \\
\hline & Taxi & $66(43.4)$ & $86(56.6)$ & $\chi^{2}=23.74(4)$ \\
\hline & Donkey cart & $0(0.0)$ & $1(100)$ & $\mathrm{P}<0.0001$ \\
\hline & On foot & $25(21.7)$ & $90(78.3)$ & \\
\hline & Much reliable & $35(67.3)$ & $17(32.7)$ & \\
\hline Reliability of taxi at odd & Less reliable & $18(40.1)$ & $26(59.1)$ & $\begin{array}{l}\chi^{2}=14.232(2) \\
\mathrm{P}=0.001\end{array}$ \\
\hline & Not reliable & $18(32.1)$ & $38(67.9)$ & \\
\hline ANC attendance & Attended & $120(39)$ & $188(61)$ & $\chi^{2}=1.115(1)$ \\
\hline ANC attendance & Did not attend & $18(31.6)$ & $39(68.4)$ & $\mathrm{P}=0.291$ \\
\hline & Excellent & $25(37.3)$ & $42(62.7)$ & \\
\hline & Good & $64(39.8)$ & $97(60.2)$ & \\
\hline $\begin{array}{l}\text { Level of satisfaction with } \\
\text { ANC }\end{array}$ & Average & $24(43.6)$ & $31(56.4)$ & $\begin{array}{l}\chi^{2}=1.145(4) \\
P=0.887\end{array}$ \\
\hline ANC & Poor & $5(33.3)$ & $10(66.7)$ & $\mathrm{P}=0.88 /$ \\
\hline & Don’t know & $3(30)$ & $7(70)$ & \\
\hline & $<\$ 2.0$ & $17(65.4)$ & $9(34.6)$ & \\
\hline & $\$ 2.0-5.0$ & $54(58.7)$ & $38(41.3)$ & \\
\hline $\begin{array}{l}\text { Cost of transport to the } \\
\text { facility }\end{array}$ & $\$ 5.0-10.0$ & $9(23.1)$ & $30(76.9)$ & $\begin{array}{l}\chi^{2}=21.369(4) \\
P<0.0001\end{array}$ \\
\hline & $>\$ 10.0$ & $15(34.1)$ & $29(65.9)$ & \\
\hline & Others & $0(0.0)$ & $1(100)$ & \\
\hline
\end{tabular}




\subsection{Independent Predictors of Utilization of Skilled Birth Attendants}

Binary logistic regression was used to identify the independent predictors of utilization of skilled birth attendants. The strongest independent predictors of utilization of SBA are education level of the mother, occupation level of the mother and husband, household monthly income, parity and transport availability and reliability. This is shown in the table 5 below.

Table 5. Independent predictors of utilization of skilled birth attendants.

\begin{tabular}{|c|c|c|c|c|c|c|}
\hline \multicolumn{7}{|c|}{ Binary Logistic Regression } \\
\hline Independent variable & Category & Used SBA n (\%) & Did not use SBA n (\%) & OR & P-value & $95 \%$ CI \\
\hline \multirow{5}{*}{$\begin{array}{l}\text { Education level of the } \\
\text { mother }\end{array}$} & Other form of education & $1(50)$ & $1(50)$ & ref & 0.001 & \\
\hline & Primary & $32(42.1)$ & $44(57.9)$ & 1.375 & 0.170 & $0.872-2.168$ \\
\hline & Secondary & $28(84.8)$ & $5(15.2)$ & 0.179 & 0.000 & $0.069-0.462$ \\
\hline & College/university & $61(98.4)$ & $1(1.6)$ & 0.016 & 0.000 & $0.002-0.118$ \\
\hline & None & $16(8.3)$ & $176(91.7)$ & 11.00 & 0.000 & $6.594-18.351$ \\
\hline \multirow{6}{*}{$\begin{array}{l}\text { Occupation of the } \\
\text { mother }\end{array}$} & Other form of occupation & $3(7.3)$ & $38(92.7)$ & ref & 0.000 & \\
\hline & No work & $39(20.0)$ & $156(80.0)$ & 4.000 & 0.001 & $2.816-5.681$ \\
\hline & Farming & $1(16.7)$ & $5(83.3)$ & 5.000 & 0.142 & $0.584-42.797$ \\
\hline & Trading & $14(45.2)$ & $17(54.8)$ & 1.214 & 0.591 & $0.599-2.463$ \\
\hline & Government employee & $64(98.5)$ & $1(1.5)$ & 0.016 & 0.000 & $0.002-0.113$ \\
\hline & Labourer /Casual & $17(63.0)$ & $10(37.0)$ & 0.588 & 0.183 & $0.269-1.285$ \\
\hline \multirow{4}{*}{ Marital status } & Widowed & $1(20.0)$ & $4(80.0)$ & ref & 0.001 & \\
\hline & Single & $2(28.6)$ & $5(71.4)$ & 2.500 & 0.273 & $0.485-12.886$ \\
\hline & Married & $134(39.8)$ & $203(60.2)$ & 1.515 & 0.000 & $1.218-1.884$ \\
\hline & Divorced & $1(6.3)$ & $15(93.7)$ & 15.000 & 0.009 & $1.981-113.556$ \\
\hline \multirow{6}{*}{ Husbands' occupation } & Other forms of work & $4(16.7)$ & $20(83.3)$ & ref & 0.001 & \\
\hline & No work & $15(35.7)$ & $27(64.3)$ & 1.800 & 0.068 & $0.958-3.384$ \\
\hline & Farming & $1(3.3)$ & $29(96.7)$ & 29.000 & 0.000 & $3.950-212.88$ \\
\hline & Trading & $45(41.3)$ & $64(58.7)$ & 1.422 & 0.070 & $0.971-2.082$ \\
\hline & Government employee & $51(77.3)$ & $15(22.7)$ & 0.294 & 0.000 & $0.165-0.523$ \\
\hline & Carpenter & $4(20.0)$ & $16(80.0)$ & 4.000 & 0.013 & $1.337-11.965$ \\
\hline \multirow{6}{*}{ Household income } & Others & $0(0.0)$ & $12(100)$ & ref & 0.000 & \\
\hline & $\$ 10-50$ & $10(14.7)$ & $58(85.3)$ & 5.800 & 0.000 & $2.965-11.347$ \\
\hline & $\$ 50-150$ & $13(14)$ & $80(86.0)$ & 6.154 & 0.000 & $3.425-11.058$ \\
\hline & $\$ 150-300$ & $31(42.5)$ & $42(57.5)$ & 1.355 & 0.200 & $0.852-2.155$ \\
\hline & $\$ 300-500$ & $34(57.6)$ & $25(42.4)$ & 0.735 & 0.243 & $0.439-1.232$ \\
\hline & $\$ 500+$ & $50(83.3)$ & $10(16.7)$ & 0.200 & 0.000 & $0.101-0.394$ \\
\hline \multirow{3}{*}{ Number of Children } & $>5$ & $19(18.4)$ & $84(81.6)$ & ref & 0.000 & \\
\hline & $1-2$ & 87 (64.9) & $47(35.1)$ & 0.540 & 0.001 & $0.379-0.770$ \\
\hline & $3-5$ & $32(25)$ & $96(75)$ & 3.00 & 0.000 & $2.011-4.476$ \\
\hline \multirow{4}{*}{$\begin{array}{l}\text { Decision making about } \\
\text { place of delivery }\end{array}$} & Relatives & $1(12.5)$ & $7(87.5)$ & ref & 0.001 & \\
\hline & Myself & $63(31.2)$ & $139(68.8)$ & 2.206 & 0.000 & $1.638-2.971$ \\
\hline & Husband & $53(46.1)$ & $62(53.9)$ & 1.170 & 0.402 & $0.811-1.688$ \\
\hline & Mother-in-law & $21(52.5)$ & $19(47.5)$ & 0.905 & 0.752 & $0.486-1.683$ \\
\hline \multirow{4}{*}{$\begin{array}{l}\text { Means of reaching health } \\
\text { facility }\end{array}$} & Other means & $2(33.3)$ & $4(66.7)$ & ref & 0.000 & \\
\hline & Own car & $21(61.8)$ & $13(38.2)$ & 0.619 & 0.174 & $0.310-1.236$ \\
\hline & Taxi & $66(43.4)$ & $86(56.6)$ & 1.303 & 0.106 & $0.945-1.796$ \\
\hline & On foot & $25(21.7)$ & $90(78.3)$ & 3.6 & 0.000 & $2.311-5.607$ \\
\hline \multirow{3}{*}{$\begin{array}{l}\text { Reliability of taxi at odd } \\
\text { hours }\end{array}$} & Not reliable & $18(32.1)$ & $38(67.9)$ & ref & 0.025 & \\
\hline & Much reliable & $35(67.3)$ & $17(32.7)$ & 0.486 & 0.015 & $0.272-0.867$ \\
\hline & Less reliable & $18(40.1)$ & $26(59.1)$ & 1.444 & 0.230 & $0.792-2.634$ \\
\hline
\end{tabular}

\subsection{Barriers to Utilization of Skilled Birth Attendants}

The study found that $62.2 \%(\mathrm{n}=227)$ of the respondents did not utilize skilled birth attendants. Among those who did not seek SBA, majority $84.2 \%(n=187)$ respondents failed to seek skilled delivery because they feared that they might undergo caesarean section, $74 \%(\mathrm{n}=168)$ due to cultural and religious beliefs, $68.7 \%(n=156)$ respondents feared to go for the same because of chances of being attended to my male nurse, $58.6 \%(\mathrm{n}=133)$ failed because they thought that TBA was available and convenient, $49.3 \%$ (112) respondents cited poor access to the hospital, $48.9 \%(\mathrm{n}=111)$ feared negligence 
by hospital staff and $36.1 \%(n=82)$ feared that they could deliver without squatting.

Other barriers cited by women during in-depth interview were that lack of SBAs, the county is a hardship area this coupled with insecurity and inter clan skirmishes had led to mass exodus of health care providers from the region. This had compromised availability of SBAs in various parts of the county especially in hard to reach areas despite facilities being available.

"The county government have built health facility, but where are nurse? Like the facility I attend there's only one nurse and sometimes many women are in labour. he is alone, what will he do?"

The means of transport at odd hours was reported to be unreliable. Women in labour had to 'trek' all the way to the hospital if they cannot afford a taxi. This was further coupled by the poor terrain with most roads being inaccessible when it rains. "Roads are poor and no vehicles to take you to the hospital in odd hours. Taxis are unreliable at night due to insecurity. The only means maybe ambulance which cannot come on time when you need... You call ambulance and will come 3-4hours later".

The women reported that the services of the TBA are much reliable, convenient and friendly. One of them complained that "In those hospitals, who holds you as you deliver? You are left alone...But see, the TBAs are always available, friendly and her services are cheap we pay her when we get something..."

Cost of transport was also mentioned as a barrier to seek services of skilled birth attendant. "Sometimes we deliver at home not because we want to, but because we do not have money to use for transport."

Religious beliefs and the parity of the mother with previous successful deliveries were also barriers to the utilization of skilled delivery services. Husbands' also determined attendance of health care facilities for ANC and subsequent delivery especially among religious fanatics.

\section{Discussion}

The study found that education was significantly associated with utilization of SBAs. The more educated a mother was the more likely that a woman will use SBA during delivery. Mothers who had secondary and tertiary education were more likely to use SBA than those with primary education or none at all. This finding concur with other studies [10], [11], [12], [13]. This could be due to the fact that more educated women might have access to both electronic and written information and have better perspectives with regards to their health and their children. Educated women tend to have more autonomy in decision making for their own reproductive health needs.

Parity was found to be a strong predictor of utilization of SBA. The higher the number of children a woman had, the less likely she was able to use Skilled Birth Attendants, those who had 1-2 children were more likely to use SBA than those who had more than 3 children. This could be attributed to the fact that these women had had their previous births without SBAs and therefore did not find any reason to deliver with them since there previous births were equally successful. It was observed that there was high fertility rate in the study area. This was echoed by the findings of KDHS 2014 that indicated a TFR of 5.2. The county also registered a CPR of only $2 \%$ according to [8].

Married women were more likely than non-married groups to utilize skilled birth attendant. This could be attributed to the fact that the decision to seek services may not be solely made by women alone as partners' approval may be needed or women found it in their own wisdom that delivering with SBAs was not necessary.

Household income was found to be a significant determinant in the utilization of skilled birth attendant. Respondents who had high monthly income were found to be more likely to use Skilled Birth Attendants. The fact that majority of the respondents were pastoralist meant that their monthly household income was low and the money could rather be spent on food than saving for delivery services. Despite the maternity services being free, it did not directly translate to the utilization of skilled delivery services as majority could not afford transport to the facility. This result concurs with the results from study by [14], who found that use of SBAs remained considerably lower among poor mothers relative to their non-poor counterparts. Occupation of both the mother and the husband was found to be significantly associated with the utilization of SBAs. Women who were working and earning some money or whose husbands were working utilized the services of skilled birth attendants than those who were not in any form of employment. The results from this study concur with the results from other studies which showed that mother's occupation played an important role in service utilization. Occupation provides opportunity for women to pay for services hence it is not surprising that this variable is a predictor of utilization of skilled birth attendance.

Transport to the facility was found to be significantly associated with the utilization of SBAs. Transport was found to be unreliable at odd hours and cost of the transport had exacerbated the condition. This was echoed by the participants during in-depth interview who reported the roads were in poor state and that there were limited vehicles that offer transport especially at odd hours and ambulances were not also reliable. This study compares with the findings of [15], who found that availability of affordable transport and the conditions of the road influence the decision to attend a service at a health facility.

The study found that attitude of the staff towards the clients influenced utilization of skilled birth attendants. This could be attributed to the fact that Kenya's (and Mandera's) public health facilities have long been plagued by reports of abuse, mistreatment, and negligence of patients at the hands of staff, a problem enhanced by poor supervision and understaffing. Patients also reported that the public health system were not culturally sensitive, failing to adapt to local circumstances such as cultures which require women to be 
attended by female practitioners and to deliver in certain positions. This could be the reason as to why many women still prefer TBAs services to SBAs. The TBAs were found to be more convenient, reliable and friendly.

The findings of this study showed that ANC attendance was high at $84.4 \%$ for those women who have visited health facility in their recent pregnancy. This value for ANC attendance was high compared to what was reported in KDHS 2014 that puts $1^{\text {st }}$ ANC visits in Mandera County at $50.5 \%$. This dramatic increase in the utilization of ANC could be attributed to devolution of health services from national government to counties and abolition of user fees by the government of Kenya. The proportion of women who delivered in health facility was $35.6 \%$ whereas the proportion who had skilled birth assistance was $37.8 \%$. This means that all deliveries in hospital were attended by SBAs and there were also other deliveries with SBAs outside public health facilities. These estimates compares well with the rates of $36 \%$ of deliveries happening in health facilities and $38.7 \%$ of deliveries attended by SBAs as observed in the [8] for Mandera county.

Despite the fact that the government of Kenya provides free maternity services in the year 2013, many deliveries still take place at home with assistance of TBA's as they are preferred for their convenience, availability, confidentiality and being helpful. However, this study established that many women now prefer to deliver in future at a health facility with assistance of skilled birth attendants as staff can provide quality services and have skills in handling deliveries and other complications of pregnancy.

\section{Conclusion}

Despite the attendance of ANC clinics being high, the level of utilization of skilled birth attendants among the study population was still low with high number of deliveries still conducted by unskilled persons at home.

\section{Recommendations}

This study recommends that the county government should come up with strategies of ensuring that women have access to education such as Adult Education Programme; economic empowerment of women through Business enterprises; the health department in the county needs to carryout behavior change interventions to educate mothers and their significant others about the significance of SBA; provide attraction and retention package for healthcare staffs especially SBAs; provision of incentives to TBAs for referral of pregnant women to the facility; strengthen referral system especially in hard to reach areas.

\section{References}

[1] WHO. (2013). Maternal mortality, Millennium Development Goal (MDG) 5. Retrieved July 11, 2015.

[2] UNICEF global databases. (2013). Delivery care-institutional deliveries. Retrieved July 01, 2015.

[3] WHO, UNICEF, The World Bank and the UNFPA. (2013). Global health observatory data: Maternal and Reproductive health.

[4] Oshonwoh, F. E., Nwakwuo, G. C., \& Ekiyor, C. P. (2014). Traditional birth attendants and women's health practices: A case study of Patani in Southern Nigeria. Journal of Public Health and Epidemiology, 6 (8).

[5] Fekadu, M., \& Regassa, N. (2014). Skilled delivery care service utilization in Ethiopia: Analysis of rural-urban differentials based on national demographic and health survey (DHS) data. Africa Health Science, 14 (4).

[6] Kenya Demographic and Health Survey. (2009). Final Report. Retrieved September 15, 2015.

[7] National Council for Population and Development (NCPD). (2013). Kenya Population Situation Analysis report. Retrieved July 18, 2015.

[8] The Kenya Demographic and Health Survey. (2014). Key Indicators. Retrieved August 11, 2015.

[9] Kenya National Bureau of Statistics (KNBS) (2009). Kenya Demographic and Health Survey 2008-09 report. Calverton, MD: KNBS and ICF Macro.

[10] Okoth, A. (2014). Utilization of Skilled Birth attendants among Women of Reproductive age in Central Division, Kajiado County, Kenya. Thesis, Kenyatta University.

[11] Babalola S., \& Fatusi, A. (2009). Determinants of use of maternal health services in Nigeria - looking beyond individual and household factor.

[12] Garg, R., Shyamsander, D., Singh, T., \& Singh, P. A. (2010). Study on Delivery Care Practices among women in Rural Punjab. Health and Population perspectives and Issues 33 (1), 23-33.

[13] Moore, M., Alex, B., \& George, I. (2011). Utilization of Health Care Services by pregnant mothers during Delivery. A. community based study in Nigeria. Journal of Medicine and Medical Sciences, 2 (5), 864-867.

[14] Pathak, P. K., Singh, A., Subramaman, S. V. (2010). Economic Inequalities in Maternal health care: prenatal and Skilled Birth Attendance in India, 1992-2006. PLoS ONE 5 (10): e13593. doi: 10. 1371/journal. pone. 0013593.

[15] Lunan, B., Clements, Z., Mahony, S., \& Hope-Jones, D. (2010). Maternal Health in Malawi: Challenges and Success. Scotland Malawi partneship. 